Journal of Computer Science 8 (2): 222-226, 2012

ISSN 1549-3636

(C) 2012 R. Moorthy et al., This open access article is distributed under a Creative Commons Attribution

(CC-BY) 3.0 license

\title{
Web-Facilitated Learning for Bioethics Principles on Human Dignity and Human Rights
}

\author{
${ }^{1}$ Ravichandran Moorthy, ${ }^{2}$ Novel Lyndon and ${ }^{2}$ Sivapalan Selvadurai \\ ${ }^{1}$ School of History, Politics and Strategy, \\ ${ }^{2}$ School of Social, Development and Environmental Studies, \\ Faculty of Social Sciences and Humanities, \\ University Kebangsaan Malaysia, 43000 Bangi, Selangor, Malaysia
}

\begin{abstract}
Problem statement: With the advent of globalization Information and Communication Technology (ICT), web-facilitated learning strategy had taken an important role in the learning and teaching process. This study examines how bioethics principles on human dignity and human rights can be learned through web-facilitated learning strategies among tertiary level international relations students. Bioethics was an emerging field that concerns states and inter-state relations. It was about thinking globally about ethics and about our moral judgment about life, the environment and other species. The objective of this study was provided an assessment on how graduate students of international relations use web-based tools to gather information about global bioethics principles. Approach: The research data was collected through feedbacks solicited from some 40 post-graduate students of international relations on (i) self-assessment on the learning acquired regarding the bioethics principles using web resources and (ii) through a set of pre- and post-tests to test the knowledge acquired on the subject matter. Results: The findings reveal that through the use of web-facilitated learning strategy respondents' showed increased comprehension and receptiveness towards bioethics principles on human dignity and human rights. Conclusion: The study concludes that the use of web-facilitated learning strategy can emphasize the importance of bioethics principles in understanding the ethical framework in dealing with human dignity and human rights. The research findings may provide useful information for scholars and researchers developing teaching strategies using bioethics resources.
\end{abstract}

Key words: Web-facilitated learning strategies, bioethics, ethics, ethical framework, human dignity, human rights

\section{INTRODUCTION}

Learning strategies refer to the activities by which the desired learning outcomes are achieved. For instance, reading aloud, copying notes, consulting peers, asking the instructor for clarification are all learning strategies. The use of learning strategies allows students to actively process information, thereby influencing their mastery of material and subsequent academic achievement (Pintrich et al., 1993). With the advent of globalization and Information and Communication Technology (ICT), web-facilitated learning strategy has taken an important role in the learning and teaching process. The abundance of information in the web had enabled both educators and students to utilize this platform for effective learning process. In fact, the web has revolutionized the way we acquire and disseminate knowledge. It has erased borders that once compartmentalize knowledge and liberalize the access to education and knowledge. Now a layman may have access to similar information, knowledge and analysis as a senior university professor. By liberalizing access to knowledge, we are directly facilitating the development of a knowledge society with knowledge come the initiatives for progress, betterment and the pursuit of social justice.

There have been several researches done on learning strategies over the last decades focusing on different aspects of this strategy. Some scholars argue that learning strategies effectively contributes to learner's competence to learn and to think. As such, by adequately employing the correct learning strategies,

Corresponding Author: Ravichandran Moorthy, School of History, Politics and Strategy, Faculty of Social Sciences and Humanities, University Kebangsaan Malaysia, 43000 Bangi, Selangor, Malaysia, Tel: +603-89215825,

Fax: +603-89213290 
students may improve their learning outcomes. Some scholars claimed that learning strategy assist students to keenly engage in self-learning activities such as seeking and processing information, task oriented and problem solving activities and facilitated thinking. More recent scientific research showed that the whole process of learning is essentially $50 \%$ learning strategy, $40 \%$ effort and $0 \%$ intelligence. Although these figures can be debated, what it essentially suggests is that the use of appropriate learning strategy will result in more effective and desirable learning outcomes amongst students (Dunkels et al., 2010).

Suggested two types of learning strategies, namely the 'deep" and 'surface' strategies. The deep strategy refers to the understanding the meaning of a given task and to satisfy curiosity. In using this strategy, a student may put in longer hours of study, make detailed notes from the text, class and web resources, complete additional exercises besides doing the minimum given tasks and assignments and will study continually rather than cram at the last minute (Vermunt, 1998) for some this strategy may be considered the highest form of learning-acquiring knowledge through the hard way. Conversely, surface learning strategy refers to memorizing facts, disjointed pieces of data, examples and illustrations (Hoeksema, 1995). In using this strategy, a student will be keener to reproduce orientation, memorize only pieces of information and be more interested in securing good grades without having to completely master the subject. In reality, numerous students using the surface strategy have been found to be successful because deep level learning are just not required to satisfy many examination requirements (Vermunt, 1998; Busato et al., 1998; Moorthy and Jeyabalan, 2011; 2012; Sankaran and Bui, 2001). Other students may be motivated by external rewards such as securing an " $A$ " grade or getting a job. To be a successful learner, Schuemer (1993) points out that the student must possess a high level of motivation.

Bioethics afford the dais for critical and responsible thinking on ethical principles that may assist individuals in decision making and foster the learning on how to balance different benefits, risk and duties. Bioethics is not about arriving at one specific correct solution to ethical problems but rather it suggests different choices made after ethical reflections (Macer, 2008; Moorthy et al., 2011). Bioethics principles on human dignity and human rights is enshrined in the Universal Declaration on Bioethics and Human Rights, which embodies a set of bioethical principles that has been agreed by 191 member states of UNESCO. This set of bioethical principles provides a common global platform by which bioethics can be introduced and strengthened within the states (Cheftel, 2008). Over the last century, with rapid progess in science and technology, many aspects of human enterprises have experienced some level of change. Consumerism, consumption, population explosion and competition for resources have brought about many challenges to human, humanity and the environment. These developments have brought about new problems and ethical issues in the likes of human rights abuses, human dignity issues, environmental degradation that threatens life on the planet and other pressing issues that concerns humankind. It appears that, in the zeal to achieve progress 4 and wealth, we have categorically neglected core human values of dignity and rights. As such, the argument set forth is that these problems require an 'ethical mindset' in its mitigation initiatives. It aims to provide moral frameworks for humans in their decisions and actions.

Although important, bioethics teaching is rather limited in many part of the world, especially in the Asia Pacific. Many of its principles are embedded in a variety of disciplines ranging from medicine to international relations. This study examines how bioethics principles on human dignity and human rights can be learned through web-facilitated learning strategies among graduate level International Relations students. Issues regarding human dignity and human rights are quite relevant to the field of International Relations and forms important component in aspects such as ethno-religious conflicts, pluralism, democracy, freedom of expression, degradation of human conditions and etc. The objective of this study was to provide an assessment on how graduate students of International Relations use web-based tools to gather information about global bioethics principles.

\section{MATERIALS AND METHODS}

Location of study area: This study was based on a survey on learning strategies activities involving 40 graduate-level International Relations students at National University Malaysia.

Data collection and analysis: Two sets of research data were collected through feedbacks solicited from respondents. The first set of data was derived from respondents' self-assessment on the learning acquired regarding the bioethics principles using web resources. Students were given a set of bioethics principles regarding human dignity and human rights (as in Table 1) and were asked to find out more information (in terms of definations, discussion and analysis) from web sources. 
Table 1: Self-assessment on learning experiences using web resources

\begin{tabular}{|c|c|c|c|c|c|}
\hline \multirow[b]{2}{*}{ Human dignity and human rights principles } & \multicolumn{5}{|c|}{ Likert scale } \\
\hline & $\begin{array}{l}1 \mathrm{Not} \\
\text { Effective }\end{array}$ & $\begin{array}{l}2 \text { Partially } \\
\text { Not Effective }\end{array}$ & $\begin{array}{l}\text { 3Partially } \\
\text { Effective }\end{array}$ & $\begin{array}{l}4 \quad 5 \text { Very } \\
\text { Effective }\end{array}$ & Effective \\
\hline \multicolumn{6}{|l|}{ Concepts of dignity in the history of ideas } \\
\hline 1. Classical antiquity & - & - & $4(10 \%)$ & $25(62 \%)$ & $11(28 \%)$ \\
\hline 2. World religion traditions & - & - & $8(20 \%)$ & $19(47 \%)$ & $13(33 \%)$ \\
\hline 3. Modern philosophy & - & - & $2(5 \%)$ & $15(38 \%)$ & $23(57 \%)$ \\
\hline 4. Contemporary humanitarian law & - & - & $8(20 \%)$ & $12(30 \%)$ & $20(50 \%)$ \\
\hline \multicolumn{6}{|l|}{ Human Dignity as intrinsic value of person } \\
\hline 1. Human dignity is an end in itself & - & 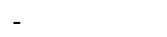 & $21(52 \%)$ & $15(38 \%)$ & $4(10 \%)$ \\
\hline 2. Equality in dignity of all human beings & - & $1(2 \%)$ & $16(41 \%)$ & $21(52 \%)$ & $2(5 \%)$ \\
\hline 3. Respect and care & - & $3(6 \%)$ & $10(25 \%)$ & $16(41 \%)$ & $11(28 \%)$ \\
\hline 4. Individual interests and welfare prior to society & - & $5(12 \%)$ & $11(28 \%)$ & $16(41 \%)$ & $8(19 \%)$ \\
\hline 5. Human dignity as a foundational concept & $2(5 \%)$ & $6(15 \%)$ & $13(33 \%)$ & $12(30 \%)$ & $7(17 \%)$ \\
\hline Diverse understanding of human dignity in different & - & - & $4(10 \%)$ & $13(33 \%)$ & $23(57 \%)$ \\
\hline $\begin{array}{l}\text { cultural and moral traditions and in different type of society } \\
\text { A person's dignity and rights entail other's } \\
\text { obligation to treat a person respectfully. }\end{array}$ & $1(2 \%)$ & $8(20 \%)$ & $12(30 \%)$ & $18(46 \%)$ & $1(2 \%)$ \\
\hline \multicolumn{6}{|l|}{$\begin{array}{l}\text { Ethical aspects of health care provider-patients relations } \\
\text { with regard to human dignity and human rights. }\end{array}$} \\
\hline 1. The problem of paternalism & $5(12 \%)$ & $11(28 \%)$ & $11(28 \%)$ & $12(30 \%)$ & $1(2 \%)$ \\
\hline $\begin{array}{l}\text { 2. In the treatment of children, elderly persons } \\
\text { and mentally handicapped individuals }\end{array}$ & $2(5 \%)$ & $9(23 \%)$ & $20(50 \%)$ & $8(20 \%)$ & $1(2 \%)$ \\
\hline 3. In palliative treatment of terminal patients & $6(15 \%)$ & $1(2 \%)$ & $16(41 \%)$ & $15(38 \%)$ & $2(5 \%)$ \\
\hline 4. In treatment of embryos and foetuses & $4(10 \%)$ & $4(10 \%)$ & $10(25 \%)$ & $18(45 \%)$ & $4(10 \%)$ \\
\hline
\end{tabular}

Based on this activity, then the respondents were asked to provide feedback on their learning experiences from this activity based on a Likert scale of 1-5 ranging from 'not effective' to 'very effective'. The second source of data was derived through a set of pre- and post-tests to assess the knowledge acquired as a result from this learning activity. Respondants were given two set of ten questions each one before undergoing the learning exercise and the second test after the learning exercise. The questions were structured at the level of 'knowledge' and 'comprehension' based on Bloom taxonomy (Bloom and Krathwohl, 1984; Lee, 1999). By comparing the the 'pre-' and 'post-tests'result, the effectiveness of this learning strategies was then assessed.

\section{RESULTS}

The research data was tabulated in two separate tables to outline the various aspects of learning strategy feedback on human dignity and human rights. Table 1 provided the statistics on respondents' self-assessment on learning experiences using web resources. Respondents gauged their learning experiences on the Likert scale of 1-5 both numerical and percentage figures were given in Table 1. Table 2 provided the preand post-tests figures in percentage. The results were broken down into 6 categories for easier analysis.

\section{DISCUSSION}

Concepts of dignity in the history of ideas: The concept of dignity is not a new phenomenon, it has existed and mentioned even in ancient Greek period.
However, in the bloody aftermath of the Second World War, the discourse on human dignity and life entered a new phase. The emergence of international law on bioethics and human rights has further expounded the concept-with almost all countries embracing at least some part of this law. As indicated in Table 1, this concept was further elaborated into four specific subconcepts-namely classical antiquity, world religion traditions, modern philosophy and contemporary humanitarian law. Classical antiquity refers to the understanding of dignity as being deserving of honor and esteem according to personal merit, inherited and achieved. In fact in ancient Greek, it was linked with human capacity of deliberation, self-awareness and free decision making. Human dignity has been also elucidated in many religions-where human beings were said to be images of the Creator and souls were equal in dignity despite their physical differences. In modern philosophy, philosopher like Kant, Hobbes and others have proposed a secular notion of human dignity. Kant's ethics of categorical imperative (to treat a person always at the same time as an end, never merely as a means) has been adopted as the foundational concept of human rights. Contemporary international law and conventions such as the Universal Declaration of Human Rights 1948, The European Convention on Human Rights and Biomedicine and other instruments and normative document of the United Nations strongly advocated human dignity and human rights amongst all people of the world irrespective of their nationality, color or creed (Cheftel, 2008). The analysis of the data shows that the respondents overwhelmingly feel that 
web-facilitated learning strategy has greatly improved their knowledge and understanding regarding the concepts. In all the four sub-categories, respondents registered more than $80 \%$ agreement as being effective and very effective. In fact in sub-categories modern philosophy and contemporary humanitarian law, respondents recorded high approval with 57 and 50\% respectively. There is no indication for the 'not effective' and 'partially not effective' categories, which clearly show that respondents feel that web resources were very useful in soliciting information regarding the subject matter.

Human dignity as intrinsic value of person: As an intrinsic value of person, the concept of human dignity can be discussed in five sub-categories. Firstly 'human dignity is an end in itself', which essential explains that unlike material values or money, human dignity has no external equivalent it is an end to itself. Secondly, devoid of public recognition of achievement, a person remains dignified as a human being as such. All human beings are equal in dignity irrespective of gender, age, social status or ethnicity. Thirdly, recognition of a person's dignity presupposes active respect for her human rights, self esteemed self determination, as well as care for her privacy, protecting her from illegitimate intrusions and preserving her valid public space. Fourthly, a society or a community should respect each of its members as a person or a moral agent on the basis of the notion of human dignity. Fifthly, respect for dignity means recognition of other's intrinsic worth as a human being (Cheftel, 2008). As indicated in Table 1, the sub-categories human dignity is an end in itself registered $48 \%$ in the 'effective' and 'very effective' categories, equality in dignity of all human beings registered $57 \%$, respect and care registered $69 \%$, individual interests and welfare prior to society registered $60 \%$ and human dignity as a foundational concept obtained $47 \%$. The figures indicate that, although not as high the previous category, this concept has registered significant approval from respondents for being effective and very effective. However it is interesting to note that several respondents, especially in the last three sub-categories feel that the learning strategies were less effective.

Diverse cultural and moral traditions: Human dignity and human rights have various manifestations as a result of its origins in different cultural and ethical traditions. Major ethical value systems such as HinduBuddhist traditions, Confucianism, Judeo-Christianity and Islam have propounded the respect for human dignity in various ways and degrees. In totalitarian societies, it appears that human dignity is less respected as compared to modern and democratic societies. Irrespective of political, cultural and religious beliefs, human dignity is universal in nature-based on the person's self-awareness and appropriate respectful treatment towards her (Cheftel, 2008). As indicated in Table 1, the data shows that respondents overwhelmingly feel that web-facilitated learning strategy has greatly improved their knowledge and understanding regarding this category with $90 \%$ respondents registering 'effective' and 'very effective' categories. Other's obligation to treat a person respectfully.

From an ethical perspective, the dignity and rights of an individual are proved by others' obligation to treat a person respectfully that is to cause no harm, not to abuse, to be fair, not to impose unwelcomed models of personal good and happiness, not to treat her merely as a means and not to consider the interest and welfare of the individual as subordinate to others' interests and welfare, to the sole interest of science and society (Cheftel, 2008). As indicated in Table 1, the data shows that $48 \%$ of respondents registering in the 'effective' and 'very effective' categories. Some $30 \%$ respondents say that it is partially effective. However another $20 \%$ say it only partially effective while another $2 \%$ has registered in ineffective.

Ethical aspects of health care provider-patients relations: In general, this category did not register high agreement among respondents as being an effective learning strategy. This concept was further elaborated into four specific concepts- namely the problem of paternalism (registers 32\% 'effective' and 'very effective'), the treatment of children, elderly persons and mentally handicapped individuals (registers 22\%), palliative treatment of terminal patients and patients in 'vegetative state' (43\%) and treatment of embryos and fetuses (registers 55\%'effective' and 'very effective'). There are also a sizeable percentage of respondents who feel that this learning strategy was not very effective, such as the problem of paternalism category registered $40 \%$ 'not effective' and 'partially not effective'.

Pre- and post-tests results: As indicated in Table 2, there was less than $30 \%$ at all levels of positive learning, which means that respondents have at least some basic level of knowledge regarding bioethic principles on human dignity and human rights. This shows that while respondents have some background knowledge of the issue at hand, their level of knowledge can be termed as basic or rudimentary. 
Table 2: Pre- and Post-tests analysis

\begin{tabular}{llrc}
\hline Categories & $\begin{array}{l}\text { Pre-test } \\
\text { (Average \% of respondents) }\end{array}$ & $\begin{array}{c}\text { Post-test (Average } \\
\% \text { of respondents) }\end{array}$ \\
\hline 1 & No learning has taken place (0\% score) & - & - \\
2 & Positive learning (below 20\% score) & 12 & - \\
3 & Positive learning (21-40\% score) & 25 & - \\
4 & Positive learning (41-60\% score) & 27 & 20 \\
5 & Positive learning (61-80\% score) & 23 & 30 \\
6 & Positive learning (81-100\% score) & 13 & 50 \\
Total & 100 & 100 & \\
\hline
\end{tabular}

However cumulatively, the figures showed that some $63 \%$ respondents have registered $41 \%$ and more in the positive learning categories. This shows that university students are exposed to the issues of bioethics, although not being part of the curriculum of studies. Meanwhile, the post-test scores illustrate that significant learning has taken place with a marked incresed from $63-100 \%$ for those who have scored $41 \%$ marks or more. No respondent scored below this mark. All respondents scored higher-which goes to show that the learning process was significantly effective in enhancing respondents' knowledge and understanding regarding bioethics principles.

\section{CONCLUSION}

The study concludes that the level of knowledge acquisition regarding human dignity and human rights, as a result of undergoing this learning strategy have significantly increased, as indicated in the pre- and post-test results. Based on the self-assessment of learning experiences using web resources, the study showed that, in general, respondents feel that web resources were quite effective in soliciting information, discussion and analysis on these bioethics principles. This implies that interactive learning by using web resources is an effective teaching-learning tool, not only to increase knowledge acquisition regarding the subject matter but also in the inculcation of ethical values related to bioethical principles. Web-facilitated learning strategies can be used as a powerful tool to dissemanite active and explorative learning on bioethics. For future research, it is recommended that scholars develop different web-facilitate learning strategy models for other principles of bioethics.

\section{REFERENCES}

Bloom, B.S. and D.R. Krathwohl, 1984. Taxonomy of Educational Objectives, Handbook 1: Cognitive Domain. 1st Edn., Longman, New York, ISBN: 0582280109, pp: 207.

Busato, V.V., F.J. Prins, J.J. Elshout and C. Harnamaker, 1998. Learning Styles: A crosssectional and longitudinal study in higher education. Br. J. Edu. Psychol., 68: 427-441. DOI: 10.1111/j.2044-8279.1998.tb01302.x
Hoeksema, L.H., 1995. Learning Strategy as a Guide to Career Success in Organizations. 1st Edn., DSWO Press, Leiden University, Leiden, ISBN: 9066951109, pp: 130.

Lee, V.S., 1999. Creating a blueprint for the constructivist classroom. University of North Carolina-Chapel Hill.

Macer, D.R.J., 2008. Moral Games for Teaching Bioethics. 1st Edn., UNESCO Chair in Bioethics, Haifa, ISBN: 9657077400, pp: 122.

Moorthy, R. and G. Jeyabalan, 2011. Environmental ethics in river water management. Am. J. Environ. Sci., 7: 370-376. DOI: 10.3844/ajessp.2011.370.376

Moorthy, R. and G. Jeyabalan, 2010. Ethics and sustainability: A review of water policy and management. Am. J. Applied Sci., 9: 24-31. DOI: DOI: 10.3844/ajassp.2012.24.31

Moorthy, R., E.A. Choy, S. Selvadurai and N. Lyndon, 2011. Bioethics principles in the teaching of climate change. Am. J. Applied Sci., 8: 962-966. DOI: 10.3844/ajassp.2011.962.966

Pintrich, P.R., D.A.F. Smith, T. Garcia and W.J. McKeachie, 1993. Reliability and predictive validity of the Motivated Strategies for Learning Questionnaire (MSLQ). Educ. Psychol. Measurement, 53: 801-813. DOI: $10.1177 / 0013164493053003024$

Sankaran, S.R. and T. Bui, 2001. Impact of learning strategies and motivation on performance: A study in web-based instruction. J. Instruct. Psychol., 28: 191-198.

Schuemer, R., 1993. Some Psychological Aspects of Distance Education. 1st Edn., ZIFF, Hagen, pp: 36.

Cheftel, J., 2008. Bioethics Core Curriculum: Section1: Syllabus Ethics Education Programme. 1st Edn., UNESCO, Paris, pp: 68.

Vermunt, J.D., 1998. The regulation of constructive learning processes. Br. J. Educ. Psychol., 68: 149171. DOI: 10.1111/j.2044-8279.1998.tb01281.x

Dunkels, E., G.M. Franberg and C. Hallgren, 2010. Interactive Media Use and Youth: Learning, Knowledge Exchange and Behavior, 1st Edn., Igi Global: ISBN: 1609602064, pp: 290. 